\title{
Algunos datos básicos son útiles para el diagnóstico de insuficiencia cardiaca en pacientes con EPOC
}

Rutten FH, Moons KGM, Cramer MJM y col. BMJ. 2005:331:1379

\section{Objetivo}

Determinar qué variables proveen información diagnóstica para el reconocimiento de insuficiencia cardíaca (IC) en pacientes con enfermedad pulmonar obstructiva crónica (EPOC) estable.

\section{Diseño}

Estudio de corte transversal ${ }^{*}$.

Lugar

Países Bajos, 51 centros de atención primaria.

\section{Pacientes}

1186 pacientes mayores de 65 años con diagnóstico de EPOC y sin diagnóstico de IC.

\section{Medición de resultados principales}

Variables de diagnóstico independientes para IC coexistente en pacientes de atención primaria con EPOC.

\section{Descripción de los tests y gold standard}

A 405 pacientes (34\% de los elegibles) se les realizó anamnesis, examen físico, ECG, radiografía de tórax, pruebas de función pulmonar, exámenes de laboratorio y ecocardiograma. El gold standard para el diagnóstico de insuficiencia cardíaca fue la opinión de un "panel de expertos". El panel utilizó todos los datos disponibles de la investigación diagnóstica, excepto el de la fracción $\mathrm{N}$-terminal del pro-péptido natriurético cerebral (NT-proBNP). Para evaluar la relación independiente de cada variable con la presencia o ausencia de IC se realizó un análisis multivariado*.

\section{Resultados principales}

La prevalencia* de nuevos diagnósticos de IC fue del 20,5\%. Las variables clínicas independientes para este diagnóstico fueron el antecedente de cardiopatía isquémica $(\mathrm{Cl})$, un índice de masa corporal (IMC) alto, un choque de la punta (latido apexiano) desplaza- do hacia fuera y una frecuencia cardíaca elevada (área bajo la curva ROC* 0,70 -IC95\% 0,64 a 0,76). El agregado de la medición del NT-proBNP ("modelo clínico reducido"), tuvo el mayor valor diagnóstico adicional con un aumento del área de la curva ROC a $0,77(0,71$ a 0,83$)$ seguido por el electrocardiograma (ECG) (área de la curva ROC 0,75 0,69 a 0,81). Ver cuadro 1

Cuadro 1. Características operativas de las variables del modelo final

\begin{tabular}{|c|c|c|c|c|c|c|c|c|}
\hline Variable & $\begin{array}{l}\text { IC } \\
(n 83)\end{array}$ & $\begin{array}{l}\sin \text { IC } \\
\text { (n 332) }\end{array}$ & $\begin{array}{l}\text { Sensibilidatat } \\
\text { (IC 95\%) }\end{array}$ & $\begin{array}{l}\text { Especificicidad } \\
\text { (CE 95\%) }\end{array}$ & $\begin{array}{c}\text { VPP } \\
\text { (IC 95\%) }\end{array}$ & $\begin{array}{l}\text { VPN } \\
\text { (IL 95\%) }\end{array}$ & $\begin{array}{l}\text { CPP } \\
\text { (IC 95\%) }\end{array}$ & $\begin{array}{l}\text { CPH } \\
\text { (IC 95\%) }\end{array}$ \\
\hline Antecedente de $\mathrm{Cl}$ & 28 & 55 & $\begin{array}{c}0,34 \\
(0,24-0,45)\end{array}$ & $\begin{array}{c}0,83 \\
(0,78-0,87)\end{array}$ & $\begin{array}{c}0,38 \\
(0,27-0,50)\end{array}$ & $\begin{array}{c}0,81 \\
(0,76-0,85)\end{array}$ & $\begin{array}{c}2 \\
(1,34-2,90)\end{array}$ & $\begin{array}{c}0,79 \\
(0,68-0,94)\end{array}$ \\
\hline IMC $>30 \mathrm{~kg} / \mathrm{m} 2$ & 27 & 51 & $\begin{array}{c}0,33 \\
(0,23-0,44)\end{array}$ & $\begin{array}{c}0,84 \\
(0,80-0,88)\end{array}$ & $\begin{array}{c}0,35 \\
(0,24-0,46)\end{array}$ & $\begin{array}{c}0,83 \\
(0,76-0,85)\end{array}$ & $\begin{array}{c}2,06 \\
(1,38-3,06)\end{array}$ & $\begin{array}{c}0,79 \\
(0,68-0,93)\end{array}$ \\
\hline $\mathrm{FC}>90 \mathrm{Ipm}$ & 20 & 44 & $\begin{array}{c}0,24 \\
(0,15-0,35)\end{array}$ & $\begin{array}{c}0,86 \\
(0,82-0,90)\end{array}$ & $\begin{array}{c}0,31 \\
(0,20-0,44)\end{array}$ & $\begin{array}{c}0,82 \\
(0,77-0,86)\end{array}$ & $\begin{array}{c}1,71 \\
(1,10-2,82)\end{array}$ & $\begin{array}{c}0,88 \\
(0,77-1)\end{array}$ \\
\hline $\begin{array}{l}\text { Choque de la punta } \\
\text { dezplazado }\end{array}$ & 22 & 48 & $\begin{array}{c}0,27 \\
(0,17-0,37)\end{array}$ & $\begin{array}{c}0,85 \\
(0,81-0,89)\end{array}$ & $\begin{array}{c}0,31 \\
(0,21-0,44)\end{array}$ & $\begin{array}{c}0,82 \\
(0,77-0,86)\end{array}$ & $\begin{array}{c}1,80 \\
(1,14-2,76)\end{array}$ & $\begin{array}{c}0,85 \\
(0,75-0,79)\end{array}$ \\
\hline VT-proBNP >14,75 pmol & 65 & 140 & $\begin{array}{c}0,78 \\
(0,68-0,87)\end{array}$ & $\begin{array}{c}0,56 \\
(0,51-0,62)\end{array}$ & $\begin{array}{c}0,32 \\
(0,25-0,39)\end{array}$ & $\begin{array}{c}0,91 \\
(0,86-0,95)\end{array}$ & $\begin{array}{c}1,77 \\
(1,52-2,13)\end{array}$ & $\begin{array}{c}0,39 \\
(0,25-0,58)\end{array}$ \\
\hline ECG anormal & 52 & 91 & $\begin{array}{c}0,63 \\
(0,51-0,73)\end{array}$ & $\begin{array}{c}0,72 \\
(0,66-0,77)\end{array}$ & $\begin{array}{c}0,36 \\
(0,28-0,45)\end{array}$ & $\begin{array}{c}0,88 \\
(0,84-0,92) \\
\end{array}$ & $\begin{array}{c}2,21 \\
(1,74-2,81)\end{array}$ & $\begin{array}{c}0,52 \\
(0,39-0,59)\end{array}$ \\
\hline
\end{tabular}

VPP: valor predictivo positivo; VPN: valor predictivo negativo; CPP: cociente de probabilidad positivo; CPN: cociente de probabilidad negativo (Ver glosario para definiciones)

\section{Conclusiones}

Datos evaluables mediante la anamnesis y el examen físico, más la determinación del NT-proBNP y el ECG ayudan a identificar IC en pacientes con EPOC estable.

Fuente de financiamiento: Funding Research grant of the Netherlands Organization for Scientific Research. Roche (Mannheim, Germany)

\section{Comentario}

La IC en la Argentina tiene una prevalencia de 1,5\%. En mayores de 65 años, alcanza el 8 a 10\%. No existe un método de diagnóstico único y éste se basa en la presencia de un conjunto de signos y síntomas inespecíficos ${ }^{1}$. Por este motivo, el diagnóstico es dificultoso, en especial en los estadios iniciales y cuando coexisten enfermedades con características similares ${ }^{2}$. En consecuencia, el ecocardiograma se ha convertido en la piedra angular para la confirmación diagnóstica y orientación etiológica. Sin embargo, no siempre está disponible o se cuenta con un operador entrenado. Este estudio jerarquiza la importancia de la anamnesis y el examen físico y demuestra que la utilización de un modelo clínico sencillo es útil para definir la presencia o ausencia de insuficiencia cardíaca, mientras que el agregado de la medición del NT-proBNP y el ECG mejoran los resultados ${ }^{3.5}$. Algunos aspectos merecen un comentario. En primer lugar, el gold standard elegido, se basó en dife-rentes parámetros de diagnóstico; uno de los cuales, el ECG, se utilizó también como variable de estudio, configurando así una definición circular que podría afectar los resultados; por otro lado los cocientes de probabilidad de las distintas variables son débiles.

\section{Conclusiones del comentador}

Se reafirma la importancia de la anamnesis y el examen físico en la evaluación y el seguimiento de nuestros pacientes. La utilización rutinaria del NT-proBNP aún no es posible en nuestro medio, pero probablemente se convertirá en futuro en una herramienta útil para complementar la evaluación diagnóstica, y proveer información pronóstica.

Horacio Argente [ Médico Especialista en Medicina Interna del Hospital de Clínicas "José de San Martín". ]

Argente $\mathrm{H}$. Algunos datos del examen físico y estudios complementarios simples son útiles para el diagnóstico de insuficiencia cardíaca en pacientes con EPOC. Evid. act. pract. ambul. 9(2): 44. Mar-Abr.2006. Comentado de: Rutten FH, Moons KG, Cramer MJ, Grobbee DE, Zuithoff NP, Lammers JW, Hoes AW. Recognising heart failure in elderly patients with stable chronic obstructive pulmonary disease in primary care: cross sectional diagnostic study. BMJ. 2005 Dec 10;331(7529):1379. PMID: 16321994.

\section{Referencias}

1. McGee S. Evidence-Based Physical Diagnosis. Philadelphia: Saunders: 2001.pp. 432-4.

2. Davie AP, Francis CM, Caruana L et al. Assessing diagnosis in heart failure: which features are any use? QJM.1997; 90:35-9.

3. Januzzi JL Jr. Natriuretic peptide testing: a window into the diagnosis and prognosis of heart failure. Cleve Clin J Med. 2006 Feb; 73(2):149-52, 155-7.

4. Camargo CA, Tung RH, Krauser DG et al. Utility of NT-proBNP for the Diagnosis of Congestive Heart Failure in Patients with Pulmonary Disease. Acad Emerg Med. 2005; 12(5) Sup 1:54-55.

5. Bozkanat E, Tozkoparan E, Baysan O, et al. The significance of elevated brain natriuretic peptide levels in chronic obstructive pulmonary disease. J Int Med Res. 2005 Sep-Oct;33(5):537-44. 